(6)

OPEN ACCESS

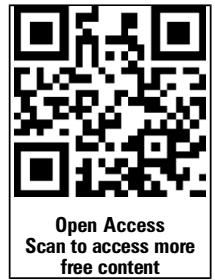

- Additional material is published online only. To view please visit the journal online (http://dx.doi.org/10.1136/ archdischild-2014-307516).

${ }^{1}$ Faculty of Medicine, University of Southampton, Southampton, UK

${ }^{2}$ Faculty of Social and Human Sciences, University of Southampton, Southampton, UK

${ }^{3}$ Developmental Science Research Department, UCL, London, UK

${ }^{4}$ Division of Health and Social Care Research, King's College London, NIHR Biomedical Research Centre at Guy's and St Thomas' NHS Foundation Trust and King's College London, London, UK ${ }^{5}$ University of Southampton and University Hospital

Southampton NHS Foundation Trust, Southampton, UK

\section{Correspondence to} Dr Colin Kennedy, Mailpoint 803G, Southampton Genera Hospital, Southampton S016 6YD, UK;

crk1@soton.ac.uk

Received 11 September 2014 Revised 6 November 2014 Accepted 9 November 2014 Published Online First 26 November 2014

\section{SLinked}

- http://dx.doi.org/10.1136/ archdischild-2014-307867

\section{CrossMark}

To cite: Pimperton $\mathrm{H}_{\text {, }}$ Blythe $\mathrm{H}$, Kreppner J, et al. Arch Dis Child 2016;101: 9-15.

\title{
The impact of universal newborn hearing screening on long-term literacy outcomes: a prospective cohort study
}

\author{
Hannah Pimperton, ${ }^{1}$ Hazel Blythe, ${ }^{2}$ Jana Kreppner, ${ }^{2}$ Merle Mahon, ${ }^{3}$ Janet L Peacock, ${ }^{4}$ \\ Jim Stevenson, ${ }^{2}$ Emmanouela Terlektsi, ${ }^{1}$ Sarah Worsfold, ${ }^{1}$ Ho Ming Yuen, ${ }^{1}$ \\ Colin R Kennedy ${ }^{1,5}$
}

\section{ABSTRACT}

Objective To determine whether the benefits of universal newborn hearing screening (UNHS) seen at age 8 years persist through the second decade.

Design Prospective cohort study of a population sample of children with permanent childhood hearing impairment (PCHI) followed up for 17 years since birth in periods with (or without) UNHS.

Setting Birth cohort of 100000 in southern England.

Participants 114 teenagers aged 13-19 years, 76 with $\mathrm{PCHI}$ and 38 with normal hearing. All had previously their reading assessed aged $6-10$ years.

Interventions Birth in periods with and without UNHS; confirmation of PCHI before and after age 9 months.

Main outcome measure Reading comprehension ability. Regression modelling took account of severity of hearing loss, non-verbal ability, maternal education and main language.

Results Confirmation of PCHI by age 9 months was associated with significantly higher mean z-scores for reading comprehension (adjusted mean difference 1.17, $95 \% \mathrm{Cl} 0.36$ to 1.97) although birth during periods with UNHS was not (adjusted mean difference $0.15,95 \% \mathrm{Cl}$ -0.75 to 1.06 ). The gap between the reading comprehension z-scores of teenagers with early compared with late confirmed PCHI had widened at an adjusted mean rate of 0.06 per year $(95 \% \mathrm{Cl}-0.02$ to 0.13$)$ during the 9.2-year mean interval since the previous assessment.

Conclusions The benefit to reading comprehension of confirmation of $\mathrm{PCHI}$ by age 9 months increases during the teenage years. This strengthens the case for UNHS programmes that lead to early confirmation of permanent hearing loss.

Trial registration number ISRCTN03307358.

\section{INTRODUCTION}

Bilateral permanent childhood hearing impairment (PCHI) of moderate, severe or profound severity is the commonest sensory disability affecting 1 in 750 children and is present at birth in more than $80 \%$ of affected children. ${ }^{1}$ PCHI of this degree has a detrimental impact on all aspects of oral language development ${ }^{2-5}$ and impacts significantly on skills that depend on language ability, such as reading and writing. 67

Identification of PCHI in early childhood enables affected children to receive early intervention to optimise their language access during a 'sensitive period' for language development. ${ }^{8}$ More than half of babies

\section{What is already known on this topic}

Universal newborn hearing screening (UNHS) is an effective way of increasing rates of early identification of congenital permanent childhood hearing impairment (PCHI).

- UNHS and early identification of PCHI are associated with benefits to language and reading outcomes in middle childhood.

\section{What this study adds}

- This study is the first to describe the effects of UNHS and early confirmation of PCHI on longer-term literacy outcomes.

- Early confirmation of PCHI was associated with significant benefits to reading comprehension in the teenage years.

- The benefit of early confirmation of PCHI to reading comprehension had increased from moderate to large between the ages of 8 and 17 years.

born with PCHI do not have prospectively identifiable risk factors so that only universal newborn hearing screening (UNHS) programmes can identify the majority of those affected. UNHS, when first introduced in the UK, more than doubled the proportion confirmed by 9 months to three-quarters of all cases of bilateral PCHI $\geq 40 \mathrm{~dB} .{ }^{9}{ }^{10}$ We have previously reported that children with $\mathrm{PCHI}$ from that birth cohort had significant benefits to language and reading at age 6-10 years associated with birth in periods with UNHS and with confirmation of PCHI by age 9 months. ${ }^{11-13}$

Systematic reviews have been increasingly supportive of UNHS ${ }^{14-16}$ and both the UK National Screening Committee and the US Preventative Services Task Force have recommended in favour of it. $^{17-19}$ During the calendar year of 2009, an estimated 5073 cases of PCHI were detected by UNHS in the USA, accounting for $43 \%$ of all detected cases of the 29 medical conditions for which newborn screening is recommended. ${ }^{20}$

Both the US Preventative Services Task Force ${ }^{15} 17$ and a 2009 WHO report on UNHS $^{21}$ have, 
however, drawn attention to the evidence gap regarding benefits beyond primary school age and benefits to functional outcomes. This study consequently aimed to provide novel evidence regarding the effects of UNHS and early confirmation of PCHI on functional outcomes in the teenage years. We report findings regarding the abilities of teenagers with PCHI at age 17 years whom we previously assessed at age 8 years. ${ }^{11}{ }^{12}$ Reading is a skill that is dependent on underlying language ability 2223 that relates very closely to educational and employment outcomes, and as such is a key functional outcome. ${ }^{24}$ Reading comprehension was therefore prespecified as the primary outcome in this study.

\section{PATIENTS AND METHODS}

The children in this prospective follow-up study, 120 children with bilateral PCHI $\geq 40$ decibels hearing level (dB HL) (not known to be postnatally acquired) and a comparison group of
63 normally hearing children, were drawn from a birth cohort of 157000 children born in eight districts of southern England (see online supplementary appendix 1), of whom about half were born in periods with UNHS. We previously reported a number of details relating to this population in infancy and first decade, including the UNHS programmes for PCHI to which they were exposed; the service provision by district and regional audiology and by other services for confirmation and management of their PCHI; and the language and reading abilities of the children at 6-10 years. ${ }^{9-13} 25-31$ Nine years after their previous language and reading assessments at 6-10 years, $76(63 \%)$ teenagers with PCHI and 38 $(60 \%)$ of the normally hearing comparison group have now participated in the study we report here (figure 1). We estimate that $49 \%$ of all oral language users with PCHI from the birth cohort had their reading assessed at age 17.1 years (see online supplementary appendix 1).

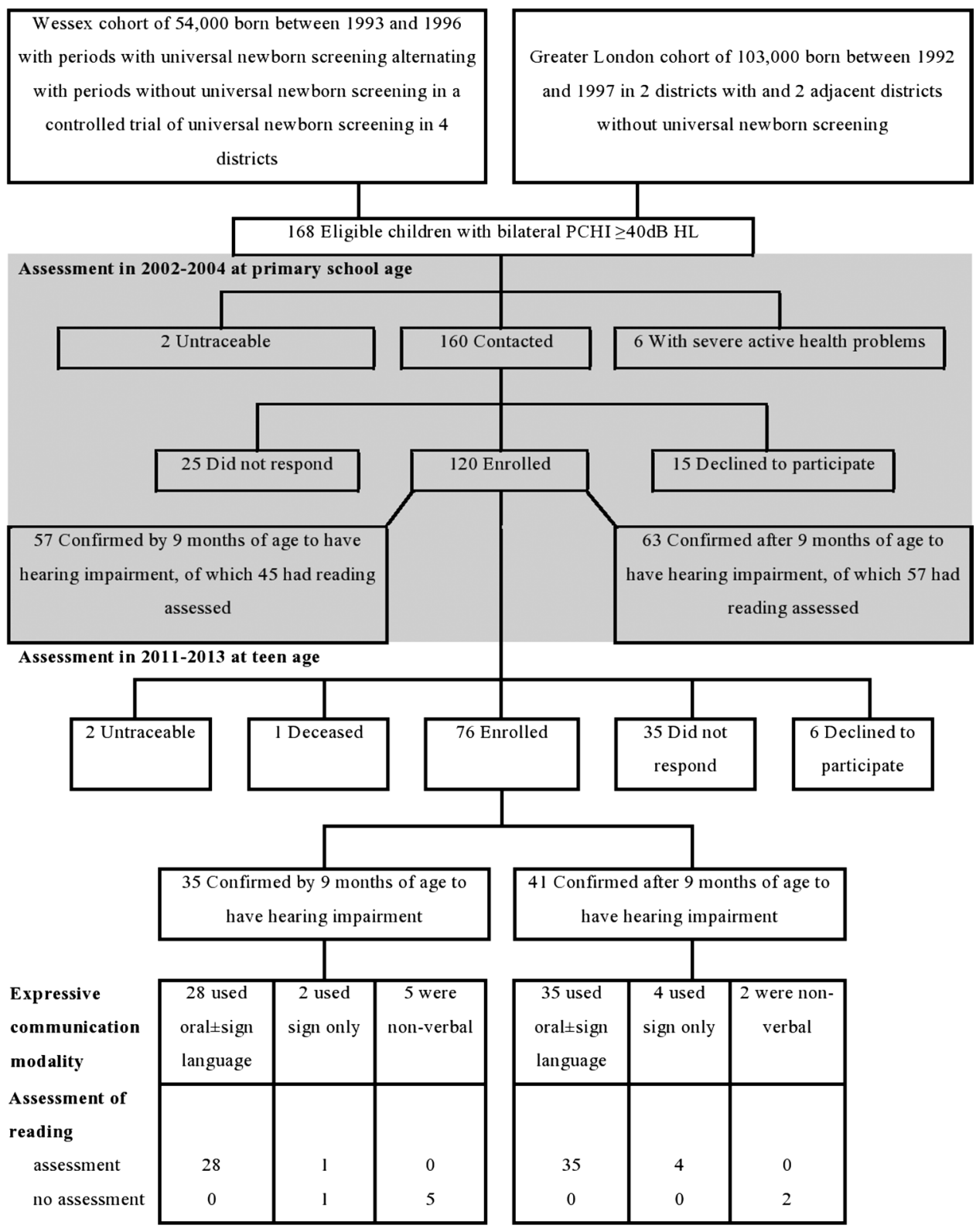

Figure 1 Numbers of teenagers with permanent childhood hearing impairment who were eligible for the study and assessed for reading ability at primary school and teenage. Greyed out section of the figure indicates the previous study at age 6-10 years. $\mathrm{dB} H \mathrm{H}$, decibels hearing level. 


\section{Procedure}

Each participant was assessed by a trained researcher, unaware of their audiological history, using the York Assessment of Reading for Comprehension Secondary Edition, ${ }^{32}$ a standardised reading test that provides measures of accuracy, comprehension and summarisation skill (see online supplementary appendix 1). A 20 min timed version ${ }^{33}$ of Raven's Standard Progressive Matrices Plus ${ }^{34}$ was used as a measure of non-verbal ability. The preplanned primary outcome of our study was reading comprehension score after adjustment in a multiple linear regression for severity of hearing loss, non-verbal ability and maternal education, which were recognised as potential confounders of the primary outcome. ${ }^{11}$ Adjusted reading accuracy and reading summarisation ability z-scores were preplanned secondary outcomes.

Severity of hearing impairment was categorised from the most recent audiological evaluation at audiology and cochlear implant clinics as moderate (40-69 dB HL), severe (70-94 dB HL) or profound ( $\geq 95 \mathrm{~dB} \mathrm{HL}$ ) according to four-frequency averaging of the pure-tone thresholds at $0.5,1,2$ and $4 \mathrm{kHz}$. Maternal education was classified according to the 2001 census in the UK.

This study was approved by the Southampton and SW Hampshire Research Ethics Committee. Written informed consent for participation in the study was obtained from principal caregivers and from the teenage participants themselves.

\section{Analysis strategies}

The primary outcome (reading comprehension) and the analysis strategy were prespecified and the statistical analysis plan was written before examination of the data. The target sample size of 96 with half of the sample born in periods with (or without) UNHS, or, in a parallel set of analyses, exposed to early (or late) confirmation of PCHI, was sufficient to have 90\% power to detect a standardised difference in the primary outcome of at least 0.67 SDs at a 5\% significance level (two sided) using a unifactorial test. We prespecified the definition of 'early' confirmation of PCHI as confirmation by nine completed months of age, consistent with the definition used in our previous trial of UNHS $^{9}$ and with the US Preventive Services Task Force benchmark for diagnosing and treating infants before 10 months of age. $^{15} 16$

The group mean and SD reading scores in the normally hearing comparison group were used to derive $\mathrm{z}$-scores for the teenagers with PCHI where the mean and SD in the normally hearing group was 0 and 1 , respectively. The z-scores in the participants with PCHI were thus expressed in terms of the number of SDs from the mean in the normally hearing comparison group. Analyses were run both with and without British Sign Language users. This did not alter the pattern of results which are therefore presented for the combined group of oral and signing communicators. Where statistically significant intergroup differences were found, subgroup analysis was then undertaken in those who had and had not received cochlear implants. The method of adjusting reading z-scores appropriately to look at change in reading ability over time comparing current scores with those previously obtained at aged 6-10 years is described in online supplementary appendix 1 .

We assessed in a linear regression model the relationships between birth during periods of UNHS or confirmation of PCHI by age 9 months and age-adjusted reading z-scores (using Stata/SE V.12.1) in oral and signing communicators (see online supplementary appendix 1). The extent to which the effect of early confirmation made a significant additional contribution to model fit after screening was included in the model was tested with a likelihood ratio test. Normality and homogeneity of the residual variance were examined for all measures to ensure that the regression models were appropriate.

\section{RESULTS}

The 114 participating teenagers were similar to the 183 who had previously participated in the study of reading and language at 7.9 years with regard to sex, non-verbal ability and maternal educational level at the time of the previous study (table 1). The 76 participants with PCHI (figure 1) were similar to the 120

Table 1 Demographic characteristics of participants and non-participants in the current study of reading ability in teenagers

\begin{tabular}{|c|c|c|c|c|}
\hline \multirow[b]{2}{*}{ Characteristic } & \multicolumn{2}{|c|}{ Children with bilateral PCHI } & \multicolumn{2}{|c|}{ Normally hearing children } \\
\hline & $\begin{array}{l}\text { Whole sample* } \\
(n=120)\end{array}$ & $\begin{array}{l}\text { Teenage sample participating } \\
\text { in present study }(n=76)\end{array}$ & $\begin{array}{l}\text { Whole sample* } \\
(n=63)\end{array}$ & $\begin{array}{l}\text { Teenage sample participating } \\
\text { in present study }(n=38)\end{array}$ \\
\hline $\begin{array}{l}\text { Mean age (SD) (range) in years } \\
\text { At primary school assessment }\end{array}$ & $\begin{array}{l}7.9(1.3) \\
(5.4 \text { to } 11.7)\end{array}$ & $\begin{array}{l}7.9(1.1) \\
(5.8 \text { to } 10.7)\end{array}$ & $\begin{array}{l}8.1(1.0) \\
(6.2 \text { to } 9.8)\end{array}$ & $\begin{array}{l}8.0(1.1) \\
(6.2 \text { to } 9.8)\end{array}$ \\
\hline Female sex n (\%) & $53(44)$ & $37(49)$ & $26(41)$ & $13(34)$ \\
\hline \multicolumn{5}{|l|}{ Severity of hearing loss $n(\%)$} \\
\hline Moderate & $62(52)$ & $38(50)$ & NA & NA \\
\hline Severe & $29(24)$ & $16(21)$ & & \\
\hline Profound & $29(24)$ & $22(29)$ & & \\
\hline Born in periods with UNHS n (\%) & $61(51)$ & $37(49)$ & NA & NA \\
\hline PCHI confirmed $\leq 9$ months $n(\%)$ & $57(48)$ & $35(46)$ & NA & NA \\
\hline English as main language at home $\mathrm{n}(\%)$ & $99(83)$ & $67(88)$ & $60(95)$ & $36(95)$ \\
\hline \multicolumn{5}{|l|}{ Maternal education $\mathrm{n}(\%)$} \\
\hline No qualifications or $<5$ 0-levels $†$ & $43(36)$ & $24(32)$ & $25(40)$ & $11(29)$ \\
\hline$\geq 5$ 0-levels or some A-levelst & $62(52)$ & $40(53)$ & $25(40)$ & $16(42)$ \\
\hline University or higher degree & $14(12)$ & $12(16)$ & $13(21)$ & $11(29)$ \\
\hline
\end{tabular}


Table 2 Characteristics of participating teenagers with hearing impairment and with normal hearing

\begin{tabular}{|c|c|c|c|}
\hline \multirow[b]{2}{*}{ Characteristic } & \multicolumn{2}{|c|}{$\begin{array}{l}\text { Children } \\
\text { with bilateral PCHI }(n=76)\end{array}$} & \multirow[b]{2}{*}{$\begin{array}{l}\text { Normally hearing } \\
\text { children }(n=38)\end{array}$} \\
\hline & $\begin{array}{l}\text { Confirmation of PCHI } \\
\text { at } \leq 9 \text { months }(n=35)\end{array}$ & $\begin{array}{l}\text { Confirmation of PCHI } \\
\text { at }>9 \text { months }(n=41)\end{array}$ & \\
\hline Mean (SD) age at assessment in years & $16.8(1.5)$ & $17.3(1.3)$ & $16.3(1.2)$ \\
\hline Female sex n (\%) & $16(46)$ & $21(51)$ & $13(34)$ \\
\hline Born in period with UNHS n (\%) & $23(66)$ & $14(34)$ & NA \\
\hline \multicolumn{4}{|l|}{ Severity n (\%) } \\
\hline Moderate* & $16(45)$ & $17(41)$ & \\
\hline Severe & $7(20)$ & $12(29)$ & NA \\
\hline Profound & $12(34)$ & $12(29)$ & \\
\hline \multicolumn{4}{|l|}{ Hearing device used $\mathrm{n}(\%)$} \\
\hline Cochlear implant/s & $7(20)$ & $8(19)$ & \\
\hline Hearing aid/s & $23(66)$ & $32(78)$ & NA \\
\hline No hearing device & $5(14) \dagger$ & $1(2) \ddagger$ & \\
\hline Mean (SD) non-verbal ability z-score§ & $-0.3(0.9)$ & $-0.3(0.8)$ & $0(1)$ \\
\hline \multicolumn{4}{|l|}{ Aetiology n (\%) } \\
\hline Syndromic & $9(26)$ & $4(10)$ & \\
\hline Other hereditary & $6(17)$ & $10(24)$ & NA \\
\hline Known non-genetic riskף & 2 (6) & $3(7)$ & \\
\hline Not known & $18(51)$ & $24(59)$ & \\
\hline \multicolumn{4}{|l|}{ Other disabilities $n(\%)$} \\
\hline Cerebral palsy & $1(3)$ & $1(2)$ & 0 \\
\hline Visual disability & 1 (3) & $1(2)$ & 0 \\
\hline Learning disability & $6(17)$ & $8(20)$ & 0 \\
\hline None of the above & $28(80)$ & $33(80)$ & $38(100)$ \\
\hline English as main language at home $\mathrm{n}(\%)$ & $34(97)$ & $36(88)$ & $36(95)$ \\
\hline \multicolumn{4}{|l|}{ Maternal education $\mathrm{n}(\%)$} \\
\hline No qualifications/<5 0-levels** & $9(26)$ & $10(24)$ & $6(16)$ \\
\hline$\geq 5$ 0-levels or some A-levels** & $17(49)$ & $21(51)$ & $14(37)$ \\
\hline University or higher degree & $9(26)$ & $10(24)$ & $18(47)$ \\
\hline
\end{tabular}

who had previously participated with regard to severity of PCHI, exposure to UNHS and confirmation of PCHI prior to nine completed months from birth (table 1). These characteristics were also similar between those who had their PCHI confirmed by age 9 months $(n=35)$ and those who had it confirmed later $(n=41)$ (table 2 ) and between those who were born in periods with UNHS $(n=37)$ and those who were not $(n=39)$ (data not shown). The early and late confirmed PCHI groups were similar with respect to the percentages affected by cerebral palsy, visual disability or learning disability (table 2). These groups were also similar in that the aetiology of deafness was identified in about half and was genetic in 34\%-43\% (table 2). The proportion of teenagers in whom English was not the main language at home was higher in the late $(12 \%)$ than the early (3\%) confirmed group and adjustment for this variable was therefore included in the regression model in addition to the three prespecified variables (see Patients and methods section).

The early and late confirmed groups showed mean reading comprehension $\mathrm{z}$-scores that were 0.63 and 1.74 SDs, respectively, below the mean reading $\mathrm{z}$-score in the normally hearing comparison group (table 3). The teenagers who had their hearing impairment confirmed by nine completed months of age had significantly higher adjusted mean z-scores than the later confirmed teenagers for both reading comprehension (1.17 SD) and reading summarisation (0.96 SD) (table 3). These effect sizes were larger in the $78 \%(51 / 65)$ who had not received cochlear implants (adjusted inter-group differences 1.29, 95\% CI 0.52 to $2.07, \mathrm{p}=0.002 ; 1.00,95 \%$ CI 0.30 to 1.70 , $\mathrm{p}=0.006$, respectively). Adjusted inter-group z-score differences on the three reading outcome measures between all teenage participants who were or were not born in periods with UNHS at birth were smaller $(0.09$ to 0.22$)$ and not statistically significant (table 3).

Change in the estimates of effect sizes and $p$ values of early confirmation and of screening was minimal when they were modelled together rather than separately, suggesting that these effects were working independently (see online supplementary table e1). Adding the effect of early confirmation into the regression model after screening was included made a significant additional contribution to model fit (likelihood ratio test 

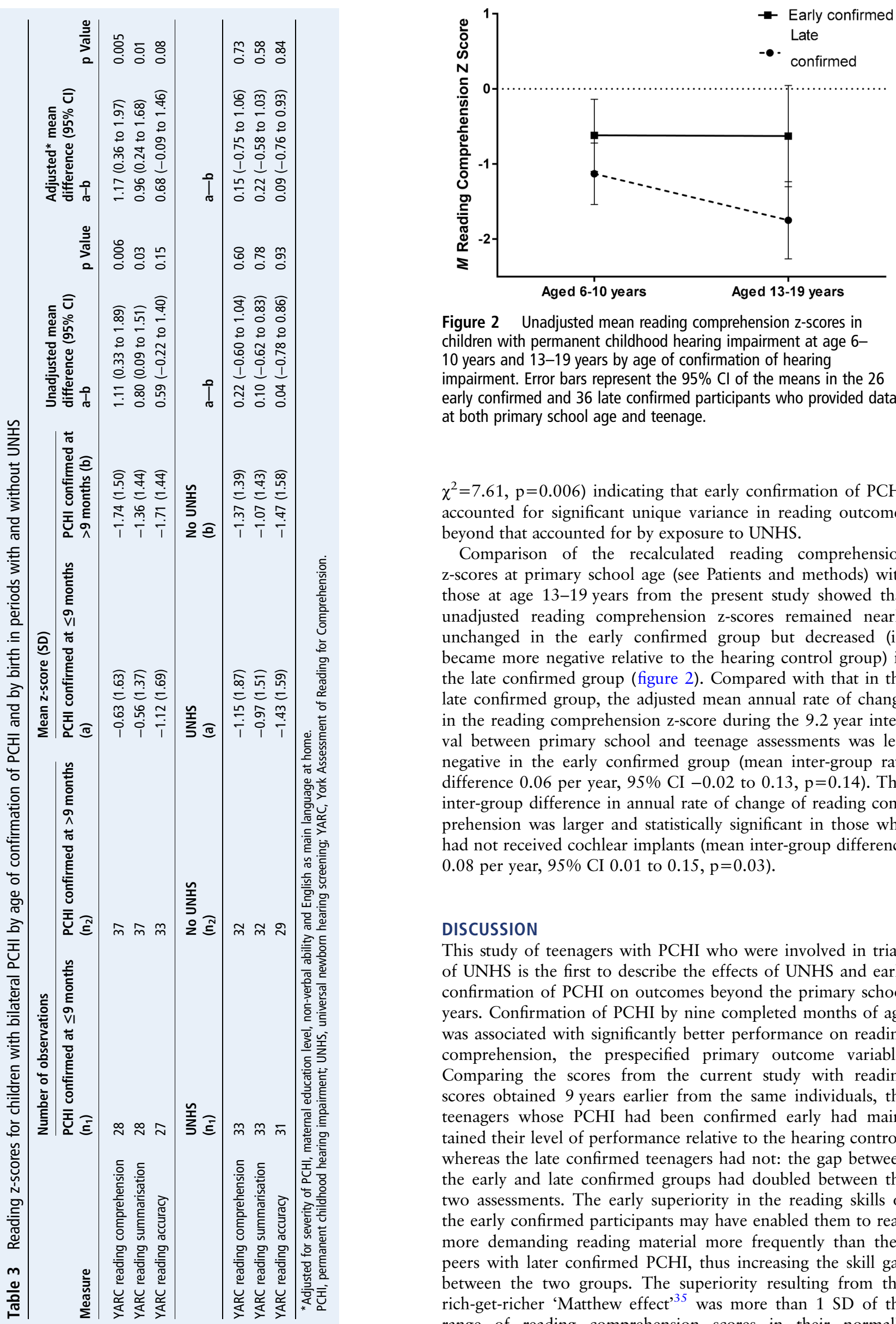

Figure 2 Unadjusted mean reading comprehension z-scores in children with permanent childhood hearing impairment at age 610 years and 13-19 years by age of confirmation of hearing impairment. Error bars represent the $95 \% \mathrm{Cl}$ of the means in the 26 early confirmed and 36 late confirmed participants who provided data at both primary school age and teenage.

$\left.\chi^{2}=7.61, \mathrm{p}=0.006\right)$ indicating that early confirmation of PCHI accounted for significant unique variance in reading outcomes beyond that accounted for by exposure to UNHS.

Comparison of the recalculated reading comprehension z-scores at primary school age (see Patients and methods) with those at age 13-19 years from the present study showed that unadjusted reading comprehension z-scores remained nearly unchanged in the early confirmed group but decreased (ie, became more negative relative to the hearing control group) in the late confirmed group (figure 2). Compared with that in the late confirmed group, the adjusted mean annual rate of change in the reading comprehension z-score during the 9.2 year interval between primary school and teenage assessments was less negative in the early confirmed group (mean inter-group rate difference 0.06 per year, $95 \% \mathrm{CI}-0.02$ to $0.13, \mathrm{p}=0.14$ ). This inter-group difference in annual rate of change of reading comprehension was larger and statistically significant in those who had not received cochlear implants (mean inter-group difference 0.08 per year, $95 \%$ CI 0.01 to $0.15, \mathrm{p}=0.03$ ).

\section{DISCUSSION}

This study of teenagers with PCHI who were involved in trials of UNHS is the first to describe the effects of UNHS and early confirmation of PCHI on outcomes beyond the primary school years. Confirmation of PCHI by nine completed months of age was associated with significantly better performance on reading comprehension, the prespecified primary outcome variable. Comparing the scores from the current study with reading scores obtained 9 years earlier from the same individuals, the teenagers whose PCHI had been confirmed early had maintained their level of performance relative to the hearing controls whereas the late confirmed teenagers had not: the gap between the early and late confirmed groups had doubled between the two assessments. The early superiority in the reading skills of the early confirmed participants may have enabled them to read more demanding reading material more frequently than their peers with later confirmed PCHI, thus increasing the skill gap between the two groups. The superiority resulting from this rich-get-richer 'Matthew effect' ${ }^{35}$ was more than 1 SD of the range of reading comprehension scores in their normally 
hearing peers and is likely to impact on their life chances through educational achievement and employment. ${ }^{24}$

Non-verbal ability was very similar in the early and late confirmed groups and adjustment for it was included in the regression model. This suggests that the deficit in reading scores in the late confirmed participants did not result from a general cognitive deficit but rather from the specific impact of delayed access to optimal language input early in life on language-related abilities. The early and late confirmed groups did not show different proportions of genetic and non-genetic aetiologies of deafness nor of disabilities additional to deafness that might account for the observed differences in reading z-scores.

Factors other than age at confirmation of PCHI appeared to determine reading outcomes for that minority of participants who had received cochlear implants ${ }^{36}$ although this subgroup analysis was not preplanned and should be treated with caution. A greater dependency of teenage reading ability of the implanted subgroup on age at implantation than on age at confirmation may explain this difference but studies of larger numbers of cochlear implantees are needed to determine this.

The effects of early confirmation were seen in those born in periods with and without UNHS and the effect of UNHS appears to be dependent on the increase in rates of early confirmation of PCHI to which it leads. The same NHS district and regional audiology teams delivered, in almost all cases, the care of both screened and unscreened and of both early and late confirmed populations in this study ${ }^{31}$ and the different outcomes between these groups are likely to reflect the effect of UNHS and of early confirmation rather than any differences in the services to which they were exposed. A 2013 birth cohort in the UK would, nevertheless, be likely to show a much stronger relationship between birth in periods with UNHS and reading outcomes. Effective postscreening audiology and other services for those screening positive for PCHI in the newborn period, which were largely absent in the period from 1992 to 1997 for the population described in this report, are now in place ${ }^{18} 19$ and therefore screening positive on UNHS in the UK would be more likely to lead to confirmation of PCHI by age 9 months.

The annual attrition rate (ie, 3\% over 17 years since UNHS or $4 \%$ over the 9 years since assessment at primary school) among children with PCHI eligible for the present study is low for a teenage population with a chronic medical condition but limited the power of the study to examine change in reading comprehension between the primary school and teenage assessments. In spite of this limitation in power, the inter-group differences on the prespecified primary outcome of reading comprehension were large enough to be both statistically significant and clinically important.

\section{CONCLUSIONS}

As the Millenium Development Goals project approaches its 2015 target, UNESCO, UNICEF, the World Bank and WHO are increasingly considering early child development, in which infant hearing is a critical component, as a key determinant of subsequent health ${ }^{21} 37$ and this report is therefore timely. Confirmation of PCHI by nine completed months of age was associated with significantly better performance on reading comprehension, the prespecified primary outcome variable, and the effect size of this benefit of early confirmation of PCHI had increased from moderate to large between assessments at the ages of 8 and 17 years. This strengthens the case for national governments to fund UNHS programmes that increase the rates of early confirmation of PCHI in the many developed and developing countries where UNHS for PCHI is currently under discussion but not yet adopted as national policy. ${ }^{38-40}$

Acknowledgements We thank the research assistants Eleanore Coulthard, Joanne Pickersgill, Lisa Shipway and Zahra Taghizadeh; the audiologists Margaret Baldwin, Alyson Bumby, Adrian Dighe, Harpreet Nijar, David Reed, Joy Roberts, Sue Robinson, Salim Suleman, Rosbin Syed and Huw Thomas; and the other medical and educational professionals who supported this study. We thank particularly the participating teenagers and their families.

Contributors HP oversaw the conduct and analysis of the study, drafted the initial manuscript and approved the final manuscript. JK, MM, JS and SW assisted in the design and supervision of the study, assisted with manuscript preparation and approved the final manuscript. JLP assisted in the design and supervision of the study, supervised the statistical analysis, assisted with manuscript preparation and approved the final manuscript. HB and ET assisted in the supervision of the study and approved the final manuscript. HMY undertook the statistical analysis and approved the final manuscript. CRK designed and supervised the study, assisted in manuscript preparation and approved the final manuscript.

Funding This work was funded by The Wellcome Trust (Grant number 089251/Z/ 09/Z) which had no role in the design, conduct of the study, collection analysis and interpretation of the data, preparation, review or approval of the manuscript, or the decision to submit the manuscript for publication.

\section{Competing interests None.}

Ethics approval Southampton and SW Hampshire Research Ethics Committee.

Provenance and peer review Not commissioned; externally peer reviewed.

Data sharing statement The authors are willing to share all unpublished data from the study with bona fide researchers. The database can be made available to them through discussion with the corresponding author and the Wellcome Trust.

Open Access This is an Open Access article distributed in accordance with the terms of the Creative Commons Attribution (CC BY 4.0) license, which permits others to distribute, remix, adapt and build upon this work, for commercial use, provided the original work is properly cited. See: http://creativecommons.org/ licenses/by/4.0/

\section{REFERENCES}

1 Davis A, Bamford J, Wilson I, et al. A critical review of the role of neonatal hearing screening in the detection of congenital hearing impairment. Health Technol Assess 1997:1:i-iv, 1-176.

2 Eisenberg LS. Current state of knowledge: speech recognition and production in children with hearing impairment. Ear Hear 2007;28:766-72.

3 Moeller MP, Tomblin JB, Yoshinaga-Itano C, et al. Current state of knowledge: language and literacy of children with hearing impairment. Ear Hear 2007:28:740-53.

4 Luckner JL, Cooke C. A summary of the vocabulary research with students who are deaf or hard of hearing. Am Ann Deaf 2010;155:38-67.

5 Luckner JL, Handley CM. A summary of the reading comprehension research undertaken with students who are deaf or hard of hearing. Am Ann Deaf 2008; 153:6-36

6 Wauters LN, Van Bon WHJ, Tellings A. Reading comprehension of Dutch deaf children. Read Writ 2006;19:49-76.

7 Conrad R. The deaf school child. London: Harper Row, 1979.

8 Thomas MSC, Johnson MH. New advances in understanding sensitive periods in brain development. Curr Dir Psychol 2008;17:1-5.

9 Kennedy CR, Kimm L, Dees DC, et al. Controlled trial of universal neonatal screening for early identification of permanent childhood hearing impairment. Lancet 1998:352:1957-64.

10 Kennedy CR, McCann D, Campbell MJ, et al. Universal newborn screening for permanent childhood hearing impairment: an 8-year follow-up of a controlled trial. Lancet 2005;366:660-2.

11 Kennedy CR, McCann DC, Campbell MJ, et al. Language ability after early detection of permanent childhood hearing impairment. NEngl J Med 2006;354:2131-41.

12 McCann DC, Worsfold S, Law CM, et al. Reading and communication skills after universal newborn screening for permanent childhood hearing impairment. Arch Dis Child 2009;94:293-7.

13 Worsfold S, Mahon M, Yuen HM, et al. Narrative skills following early confirmation of permanent childhood hearing impairment. Dev Med Child Neurol 2010;52:922-8

14 Pimperton $\mathrm{H}$, Kennedy CR. The impact of early identification of permanent childhood hearing impairment on speech and language outcomes. Arch Dis Child 2012;97:648-53.

15 Nelson HD, Bougatsos C, Nygren P. Universal newborn hearing screening: systematic review to update the 2001 US Preventive Services Task Force Recommendation. Pediatrics 2008;122:E266-E76. 
16 Thompson DC, McPhillips H, Davis RL, et al. Universal newborn hearing screening - Summary of evidence. JAMA-J Am Med Assoc 2001;286:2000-10.

17 Calonge N, Petitti DB, DeWitt TG, et al. Universal screening for hearing loss in newborns: US preventive services task force recommendation statement. Pediatrics 2008;122:143-8.

18 Bamford J, Uus KI, Davis A. Screening for hearing loss in childhood: issues, evidence and current approaches in the UK. J Med Screen 2005;12:119-24.

19 Public Health England. NHS Newborn Hearing Screening Programme 2013 [cited 2013 06.09]; http://hearing.screening.nhs.uk/

20 Howell RR, Terry S, Tait VE, et al. CDC grand rounds: newborn screening and improved outcomes. MMWR Morb Mortal Wkly Rep 2012;61:390-3.

21 World Health Organization. Newborn and infant hearing screening: Current issues and guiding principles for action. Geneva: WHO Press, 2009.

22 Fricke S, Bowyer-Crane C, Haley AJ, et al. Efficacy of language intervention in the early years. J Child Psychol Psychiatry 2013;54:280-90.

23 Tunmer WE, Chapman JW. The simple view of reading redux: vocabulary knowledge and the independent components hypothesis. J Learn Disabil 2012;45:453-66.

24 Dugdale G, Clark C. Literacy changes lives: an advocacy resource. London: National Literacy Trust; 2008.

25 Watkin PM, Baldwin M. Confirmation of deafness in infancy. Arch Dis Child 1999;81:380-9.

26 Tucker SM, Bhattacharya J. Screening of hearing impairment in the newborn using the auditory response cradle. Arch Dis Child 1992;67:911-19.

27 Petrou S, McCann D, Law CM, et al. Health status and health-related quality of life preference-based outcomes of children who are aged 7 to 9 years and have bilateral permanent childhood hearing impairment. Pediatrics 2007;120:1044-52.

28 Schroeder L, Petrou S, Kennedy CR, et al. The economic costs of congenital bilateral permanent childhood hearing impairment. Pediatrics 2006;117:1101-12.
29 Stevenson J, McCann D, Watkin P, et al. The relationship between language development and behaviour problems in children with hearing loss. J Child Psychol Psychiatry 2010;51:77-83.

30 Stevenson J, McCann DC, Law CM, et al. The effect of early confirmation of hearing loss on the behaviour in middle childhood of children with bilateral hearing impairment. Dev Med Child Neurol 2011;53:269-74.

31 Watkin P, McCann D, Law C, et al. Language ability in children with permanent hearing impairment: the influence of early management and family participation. Pediatrics 2007;120:E694-701.

32 Stothard SE, Hulme C, Clarke P, et al. YARC York Assessment of Reading for Comprehension Secondary. GL Assessment; 2010.

33 Hamel R, Schmittman VD. The 20-minute version as a predictor of the Raven Advanced Progressive Matrices Test. Educ Psychol Meas 2006;66:1039-46.

34 Styles I, Raven M, Raven JC. Standard progressive matrices-plus version. London: Pearson; 1998.

35 Stanovich KE. Matthew effects in reading: some consequences of individual differences in the acquisition of literacy. Read Res Q 1986;21:360-407.

36 Markman TM, Quittner AL, Eisenberg LS, et al. Language development after cochlear implantation: an epigenetic model. J Neurodev Disord 2011;3:388-404.

37 Olusanya BO. Highlights of the new WHO Report on Newborn and infant hearing screening and implications for developing countries. Int J Pediatr Otorhinolaryngol 2011;75:745-8.

38 Liang Q, Mason B. Enter the dragon-China's journey to the hearing world. Cochlear Implants Int 2013;14(Suppl 1):S26-31.

39 Olusanya BO. Neonatal hearing screening and intervention in resource-limited settings: an overview. Arch Dis Child 2012;97:654-9.

40 The Canadian Association of Speech-Language Pathologists and Audiologists. Universal Newborn Hearing Screening. 2013 [cited 2013 22.12]; http://www.caslpa. ca/caslpa-work/universal-newborn-hearing-screening 